\title{
Los repertorios militares: contribución a la historia de la lexicografía de especialidad ${ }^{*}$
}

\author{
MARTA SÁNCHEZ ORENSE
}

Universidad de Murcia

\section{INTRODUCCIÓN}

Uno de los capítulos más interesantes de la historia de la lexicografía española es el conformado por los numerosos repertorios lexicográficos dedicados en exclusiva al análisis de la profusa terminología militar existente en castellano. Tras la aparición, en 1749, del primero de estos diccionarios militares, obra de Raimundo Sanz, el panorama lexicográfico de nuestra lengua experimenta una auténtica eclosión en lo que respecta a la elaboración de glosarios, vocabularios y diccionarios encargados de recopilar y definir el léxico de la milicia.

En este trabajo nos proponemos reconstruir la etapa más importante de esta lexicografía especializada, a saber, la transcurrida entre el año 1749 , fecha que señala el inicio de esta peculiar modalidad lexicográfica, y el final del siglo XIX, momento en que la proliferación de este tipo de obras comienza a decaer.

En primer lugar, dado su indudable valor metalexicográfico, partimos del análisis de los prólogos confeccionados por casi todos los autores con el fin de servir de complemento a su labor lexicográfica. Sin olvidar las ideas esbozadas en los prólogos, expondremos las principales características del corpus lexicográfico manejado, con especial hincapié en los aspectos que más nos han llamado la atención, además de rastrear las influencias de unos lexicógrafos en otros, asunto de vital trascendencia en este tipo de producciones científicas.

El presente trabajo surge del convencimiento de la relevancia de los diccionarios militares del español. Destacamos, entre otros valores, su capacidad para evidenciar la gran riqueza lingüística de que goza nuestra terminología militar, además de constituir unos magníficos representantes de esta técnica lexicográfica tan particular. Con nuestra presentación, esperamos contribuir a una mejor difusión de todos estos repertorios, que hasta ahora apenas han tenido repercusión, debido quizá a la propia especificidad del ámbito en el que se inscriben.

\section{LOS DICCIONARIOS MILITARES DEL SIGLO XVIII}

Debemos precisar que para esta investigación hemos descartado atender los diccionarios militares bilingües o multilingües en los que una de las lenguas involucradas es

\footnotetext{
* Este trabajo es resultado del proyecto de investigación 19296/PI/14, financiado por la Fundación Seneca-Agencia de Ciencia y Tecnología de la Región de Murcia en el marco del PCTIRM 2011-2014. 
el español. Curiosamente, el inicio de esta lexicografía especializada plurilingüe se sitúa también en el siglo XVIII: A pocket vocabulary in six languages, viz. English, German, Dutch, French, Italian and Spanish; containing such words, terms and questions, as are most generally in use, particularly in military service (1794), del capitán James Willson, precursor de una larga lista de diccionarios de idéntica temática y con características similares ${ }^{1}$.

\subsection{El Diccionario militar (1749) de Raimundo Sanz}

Este Diccionario militar tiene el mérito de ser el primer trabajo lexicográfico en lengua española sobre vocabulario militar ${ }^{2}$. Como ya se indica en la portada, se trata de una «traducción del idioma francés en el español». Y es en la cédula real donde encontramos más información al respecto:

Por quanto por parte de vos Don Raymundo Sanz, Capitán de Minadores del primer Batallón de Artillería, se me ha representado teníais traducido del idioma francés al español un tomo en octava, con el título de Diccionario Militar, o Recopilación Alphabética de todos los términos propios al Arte de la Guerra, y que el nombre del Autor era solamente el que se encontrava en la Dedicatoria que hacía al Príncipe de Turena, y se reconocía por A. D. L. C. que deseando dar esta obra a la luz pública, me suplicasteis fuesse servido concederos licencia y privilegio por diez años para su impressión (Sanz 1749: XIV ${ }^{3}$ ).

Gago-Jover (2007: 61) nos informa de que la obra lexicográfica francesa que traduce Sanz es la de Aubert de la Chesnaye-Desbois (Dictionnaire militaire, ou, Recueil alphabetique de tous les termes propres à l'art de la guerre), publicada en París en 1742. Siguiendo a García Platero (2003: 266), «durante este siglo [el XVIII] se publican muchos diccionarios monolingües especializados, si bien la mayor parte de las veces podemos hablar únicamente de traducciones», lo que demuestra que el repertorio de Sanz no es un ejemplo aislado.

Ahora bien, «en contra de lo que inicialmente pudiéramos suponer, la labor de Raimundo Sanz no se limita a la traducción literal del original francés, sino más bien a la adaptación a la lengua y cultura militar españolas de una obra francesa» (Gago-Jover y Tejedo-Herrero 2007: X). Además, como reconoce el propio Sanz en su prólogo:

El curioso notará cotejando el original con la traducción que en partes he sido breve, en algunas dilatado y en otras no hago mención. En lo primero me ha parecido conveniente que una sucinta y clara explicación es bastante, sin tanta digressión. En lo segundo, como propio de mi facultad, he aplicado lo que corresponde a nuestro uso. $\mathrm{Y}$ en lo tercero he passado en silencio lo que he creído no ser essencial, a fin de no augmentar el volumen, pero todo sin salir del orden de traductor (Sanz 1749: XVIII).

\footnotetext{
${ }^{1}$ Como el Vocabulario militar francés e inglés-español (1853) de Enrile, el Vocabulario militar español-alemán (1885) de Garrido y el Vocabulaire militaire espagnol-français (1889) de Trépied.

${ }^{2}$ A finales del siglo XVIII hay una nueva edición del mismo: Madrid 1794, Oficina de D. Gerónimo Ortega y herederos de Ibarra. Por otro lado, la edición moderna del Diccionario militar de Sanz se la debemos a Gago-Jover y Tejedo-Herrero (2007).

${ }^{3}$ Debe notarse que la paginación en números romanos no aparece en el original.
} 
Es evidente que para Sanz la actividad traductora no sólo consiste en volcar una obra que está escrita en una determinada lengua a otra distinta, sino que para que el producto final sea legítimo es necesario que el traductor intervenga en ella de manera mucho más directa. De este modo, Sanz se ve obligado a adoptar una serie de decisiones, que posibilitan el surgimiento de un repertorio lexicográfico en lengua castellana bastante alejado del francés que lo motiva. De acuerdo con Gago-Jover y TejedoHerrero (2007: XI-XIII), Sanz elimina de su obra, en primer lugar, la mayoría de las referencias a la historia o a las instituciones francesas presentes en la de Aubert de la Chesnaye-Desbois. En segundo lugar, cuando considera que es necesario concretar el uso o la función de una determinada realidad militar, amplía la definición del término que la designa. Y, por último, prescinde de aquellas entradas que considera obsoletas, exclusivas de Francia o cuyas definiciones son muy parecidas a las que ya poseen otros lemas.

\subsection{La Encyclopedia metódica (1791-1792) de Luis Castañón}

En 1791 y 1792 la imprenta de Sancha (Madrid) publica dos tomos de la Encyclopedia metódica dedicados a la milicia. Se trata, de nuevo, de la traducción de una obra francesa, la Encyclopédie méthodique, vasta empresa lexicográfica dispuesta por orden de materias. En el original francés, la parte de la milicia fue redactada por Louis-Félix Guinement de Kéralio, mientras que el encargado de traducirla a nuestra lengua fue Luis Castañón. Pero, al igual que Sanz, no se limitó a una mera traducción: como en la misma portada se adelanta, éste es un texto dedicado al arte militar y «traducido del francés al castellano con algunas adiciones por el teniente coronel de infantería don Luis Castañón».

En el «prólogo del traductor» se explica en qué consisten exactamente sus intervenciones: «Los artículos que principian con esta señal (N.) son nuevos; esto es, aumentados en la traducción; y lo contenido entre dos estrellitas o asteriscos, adicciones del Traductor» (Castañón 1791: VII) ${ }^{4}$.

Le sigue el «discurso preliminar», que es ya obra del francés Kéralio. Y tras él se inserta el repertorio lexicográfico, que es básicamente enciclopédico, de ahí que sus artículos sean, por lo general, extremadamente amplios y con abundantes referencias históricas. Una buena muestra la constituye el de batalla, que ocupa más de 100 páginas, y donde resulta evidente que la incorporación de detalladas explicaciones sobre cada una de las batallas más importantes del último cuarto del siglo XVII y de los primeros años del XVIII, como la de Cassel, San Dionisio, Marsella, Cassano, etc., ha contribuido de manera decisiva a su desmesurada extensión.

De hecho, pese a la amplitud de cada uno de los dos tomos (poseen 563 y 632 páginas respectivamente), su macroestructura está incompleta al no incluir todas las letras del abecedario. El primer volumen abarca desde la letra $a$ hasta $c a z$ (su última palabra es cazadores), mientras que el segundo se extiende desde ce (ceguera) hasta gua (guarnición).

\footnotetext{
${ }^{4}$ Tampoco en este caso la paginación en números romanos procede del original.
} 


\section{LOS DICCIONARIOS MILITARES DEL SIGLO XIX}

Para este trabajo también hemos creído conveniente prescindir de aquellos repertorios interesados únicamente en los tecnicismos propios de ramas militares muy concretas, como pueden ser la artillería y la armería, o que simplemente guardan una mera relación casual con el arte militar, como ocurre con la ingeniería. De los dos siglos contemplados, este tipo de obras solo hacen acto de presencia en el segundo de ellos, esto es, en el XIX. Son ejemplos de esta otra corriente lexicográfica tanto el Vocabulario técnico del material de artillería e ingenieros (1853) de Tamarit como el Diccionario ilustrado de los pertrechos de guerra (1853-1866) de Agar.

\subsection{El Diccionario militar portátil (1822) de Fernández Mancheño}

Su título completo es Diccionario militar portátil o recopilación alfabética de todos los términos propios de las ciencias militares, explicación de los empleos de la milicia $y$ sus obligaciones, $y$ de las diferentes especies de tropas, clases distintas de armas antiguas y modernas, máquinas de guerra, etc., etc. Se trata del primer diccionario militar de nuestra lexicografía plenamente original.

Uno de sus aspectos más llamativos es el relativo a la inclusión de una «explicación de las abreviaturas usadas en esta obra», donde, junto a marcas como Fort. (Fortificación), Est. (Estrategia) y Táct. (Táctica), constatamos la presencia de otras en principio ajenas a la milicia: Alg. (Álgebra), Arit. (Aritmética), Ast. (Astronomía), Geom. (Geometría), Geog. (Geografía), Hid. (Hidráulica), Mat. (Matemática), etc. Fernández Mancheño justifica este modo de proceder en su «discurso preliminar»:

Existe una porción de otras ciencias, cuya utilidad no podrá menos de conocer el observador curioso, y que aunque a primera vista no parezcan propias [de la profesión de las armas] son de suma importancia, especialmente en tiempo de guerra (Fernández Mancheño 1822: VI).

$\mathrm{Al}$ cotejar algunas definiciones del presente repertorio con las del Diccionario militar de Sanz, se hace patente que Fernández Mancheño tuvo muy presente el primer vocabulario militar del español:

\begin{tabular}{|l|l|}
\hline \multicolumn{1}{|c|}{ Sanz (1749) } & \multicolumn{1}{|c|}{ Fernández Mancheño (1822) } \\
\hline $\begin{array}{l}\text { Galería para passo de fosso. Es un pequeño } \\
\text { passadizo hecho de carpintería que en piezas de } \\
\text { madera se lleva al fondo del fosso, y le cubren de } \\
\text { tablas cargadas de tierra para que pueda passar el } \\
\text { minador y resista a los fuegos de artificio, y a las } \\
\text { piedras que el enemigo echa sobre él. }\end{array}$ & $\begin{array}{l}\text { Galería. fort. Para paso de foso. Es una } \\
\text { especie de corredor en arco, que en piezas } \\
\text { de madera se lleva al fondo del foso, y le } \\
\text { cubren de tablas cargadas de tierra para } \\
\text { que pueda pasar el minador y resista a los } \\
\text { fuegos artificiales y a las piedras que el } \\
\text { enemigo echa sobre él. }\end{array}$ \\
\hline $\begin{array}{l}\text { Ronda. Es una patrulla que hace de noche un } \\
\text { oficial al rededor del rampar o muralla de una } \\
\text { plaza de guerra para observar si los centinelas } \\
\text { hacen su dever con vigilancia y fidelidad. El } \\
\text { oficial que va de ronda hace llevar una luz o } \\
\text { mecha encendida. El camino de las rondas está } \\
\text { delante del parapeto, a lo alto del terraplén, y es } \\
\text { de tres a quatro pies de ancho. Sirve para dar la }\end{array}$ & $\begin{array}{l}\text { Ronda. Es una patrulla que hace de no- } \\
\text { che un oficial al rededor del rampar o } \\
\text { suralla de una plaza de guerra para ob- } \\
\text { vigilancia y fidelidad. }\end{array}$ \\
una luz o cabo de mecha encendida. \\
Las rondas se conocen con los nombres
\end{tabular}




\begin{abstract}
buelta al rededor de la plaza y descubrir lo que huviere en el fosso. Quando el gobernador o teniente de rey de la plaza hacen la ronda, los oficiales de guardia están obligados a poner los soldados en una fila, pero sin armas, y salirlo a recibir, adelantándose algunos passos para darle el santo. Las otras rondas deben dar el santo al sargento o cabo de esquadra, que los recibe con la espada desnuda y la punta acia el pecho del que lo da. Desde que el centinela aperciba la ronda, dice gritando: ¿Quién vive? Y tan alto, que el cuerpo de guardia lo pueda oír bien, y responden: Ronda de gobernador, ronda de mayor, etc. El centinela que está más vecino al cuerpo de guardia, después de haverle dicho: Deténgase allá, llama gritando: Cabo de esquadra de guardia, la ronda $[\ldots]$.
\end{abstract}

de mayor $\mathrm{u}$ ordinaria. La mayor es la que hace el gobernador, teniente de rey $o$ sargento mayor, y la ordinaria la arriba dicha.

En este último caso, el de ronda, puede observarse que Fernández Mancheño no se limita a reproducir literalmente la definición de Sanz, sino que elimina todo lo que considera superfluo. Es precisamente esta una de sus principales características.

Por otro lado, la influencia que el Diccionario de Autoridades ejerce sobre esta obra lexicográfica constituye otro de sus rasgos fundamentales. En este sentido, en el artículo contra fuertes o estribos puede apreciarse la enorme deuda contraída por Fernández Mancheño tanto con el Diccionario académico como con el Diccionario militar de Sanz:

\begin{tabular}{|c|c|c|}
\hline Aut. & Sanz (1749) & Fernández Mancheño (1822) \\
\hline $\begin{array}{l}\text { Contrafuerte. El fuerte que } \\
\text { se hace en oposición de otro. } \\
\text { No tiene uso. } \\
\text { Term. de los Guarnicioneros. } \\
\text { Correa de vaqueta de dos } \\
\text { dedos de ancho y más de } \\
\text { tercia de largo, la qual se } \\
\text { clava en el fuste delantero de } \\
\text { la silla y en el de respaldo, } \\
\text { para assegurar en ella las } \\
\text { cinchas con que se afianza la } \\
\text { silla. }\end{array}$ & $\begin{array}{l}\text { Contra-fuertes o estribos. } \\
\text { Son ciertos pilares o prismas } \\
\text { de muralla distantes uno de } \\
\text { otro, de quince hasta a vein- } \\
\text { te pies, y se construyen } \\
\text { desde sus cimientos con un } \\
\text { gran talud que va a fenecer } \\
\text { su cola en el cordón. Sirve } \\
\text { para fortalecer la muralla, } \\
\text { sobstener el terraplén y el } \\
\text { camino de las rondas. }\end{array}$ & $\begin{array}{l}\text { Contra fuertes o estribos. } \\
\text { fort. Son ciertos pilares o } \\
\text { prismas de muralla, distantes } \\
\text { uno de otro de } 15 \text { a } 20 \text { pies, y } \\
\text { se construyen desde sus ci- } \\
\text { mientos con un gran talud; } \\
\text { que va a fenecer su cola en el } \\
\text { cordón. Sirve para fortalecer } \\
\text { la muralla y sostener el terra- } \\
\text { plén, etc. } \\
\text { Es también el fuerte que hace } \\
\text { oposición a otro. } \\
\text { Es una correa de baqueta de } \\
\text { dos dedos de ancho, que se } \\
\text { clava en los fustes de la silla } \\
\text { para asegurar las cinchas que } \\
\text { la afianzan. }\end{array}$ \\
\hline
\end{tabular}

Pese a lo limitado de la muestra, confirmamos que el trasvase de definiciones entre estos tres repertorios fue constante. 
3.2. El Ensayo de un diccionario razonado sobre la ciencia de la guerra (1826) de Sánchez Cisneros

El propio autor de esta obra, en las advertencias «al lector», la califica de «ensayo ligero o pequeño Diccionario enciclopédico de la ciencia de mi Instituto». De esta forma, no debe sorprendernos que formen parte de su macroestructura unidades pluriverbales como: abundancia de forrages y subsistencias, atributos esenciales de la estrategia, calidad de tropas para los ataques de mano, faltas estratégicas, motivos de la pérdida de las batallas, etc. También la extensión de sus artículos ratifica el proceder enciclopédico del autor.

Por otro lado, Sánchez Cisneros admite basarse en obras anteriores a la suya, si bien deja patente la aportación de nuevos datos. En este sentido precisa haberse dedicado a asuntos militares hasta ahora no tratados. Anhela, por consiguiente, que nadie pueda atreverse a tachar su obra de simple copia:

Me dirás quizás, Lector mío, que repito en mi obra lo que otros hombres eminentes han dicho, y yo te diré que es cierto en cuanto a la esencialidad de las doctrinas, mas no en el modo de exponerlas y esplanarlas; aquí hay caudal mío y ageno, y en muchas cosas parto de mi pobre cholla; esto puedo asegurarte para que no me trates de plagio, pues hay pocos sabios que se desdeñen de caminar por las sendas de sus maestros, aunque con alguna libertad de separarse cuando lo crean conveniente, porque todos nos equivocamos (Sánchez Cisneros 1826: VIII-IX).

Resulta curioso que al final de la parte lexicográfica se adjunte una «nota particular sobre el levantamiento de planos topográficos».

\subsection{El Diccionario militar español-francés (1828) de Federico Moretti}

Esta obra comienza con la dedicatoria del napolitano Federico Moretti al rey Fernando VII. A continuación inserta el «prólogo», en el que especifica las características más relevantes de su repertorio. Nos encontramos, en este caso, ante un verdadero diccionario de lengua, muy distinto de, por ejemplo, la Encyclopedia metódica o el Ensayo de un diccionario razonado sobre la ciencia de la guerra. Para los distintos lemas, Moretti recurre a definiciones de tipo lingüístico, en consonancia con sus propósitos:

Ala. s. f. Tact. Aile. La parte de tropa que cubre el centro del ejército por cualquiera de los costados.

Pertrechar. v. a. Munir. Reforzar o abastecer de municiones y defensas una plaza, fortaleza o sitio de campaña.

Admite, no obstante, que se ha apartado en varias ocasiones de este propósito:

Si alguna vez me he separado de este principio, adoptando algunas voces latinas, es porque de otro modo no me hubiera sido posible explicar la táctica, la castrametación, las armas y ordenanzas de los griegos, romanos, galos, cántabros, etc. (Moretti 1828: X).

En este sentido, las definiciones más extensas y enciclopédicas suelen hacer acto de presencia en los artículos correspondientes a realidades propias de épocas militares anteriores, como en la caracterización de los distintos ingenios bélicos empleados por los romanos: 
Ballesta. s. f. ant. Arbaléte. Máquina neurobalística que servía para arrojar piedras, saetas, etc. Esta arma se componía de un arco de madera, de cuerno o de acero, que atravesaba un fuste de madera de un pie y medio hasta tres de longitud, y algunas veces más. El fuste tenía en el medio una pequeña abertura o hendidura de dos dedos de largo y en ella una ruedecita de acero sólida y movible, por cuyo centro pasaba un tornillo que le servía de eje. La rueda salía en parte por encima del caballete y tenía una muesca para asegurar la cuerda de la ballesta cuando estaba tendida [...].

De todas formas, es posible hallar definiciones enciclopédicas en términos que designan realidades contemporáneas a Moretti, si bien es cierto que se trata de casos aislados:

Parapeto. s. m. Fort. Parapet. Parte superior de una muralla, formada de una masa de tierra a prueba de cañón, que se eleva por la parte anterior del terraplén y sirve para cubrir la tropa destinada a la defensa de aquella muralla. Su espesor debe ser de diez y ocho a veinte pies, y su altura de seis de parte de la plaza, y de cuatro a cinco de parte de la campaña. Esta diferencia de altura forma debajo del parapeto un declive o pendiente, que facilita a los soldados que guarnecen el parapeto el poder tirar de alto a bajo al foso [...].

Hay incluso artículos en los que Moretti aporta su opinión sobre el tema en cuestión, en lugar de limitarse a ofrecer una definición para los mismos:

Policía militar. s. f. Police militaire. La policía de los ejércitos se ha limitado a muy poca cosa hasta lo presente, o se la ha confundido con la disciplina; pero estas partes son infinitamente distintas, pues si sólo se considera un ejército como destinado a obrar contra los enemigos del estado, entonces es un cuerpo puramente militar, a quien es necesaria una disciplina; mas cuando se trata de los medios de procurar a los individuos que componen este ejército el alimento, el vestido y demás comodidades, como de libertarles de los males que intentan introducirse por todas partes [....].

Como puede comprobarse, por lo general el napolitano inserta entre las marcas y la definición su equivalente en francés. El último de los cuatro apéndices de los que dota a su diccionario ${ }^{5}$ está formado por el Vocabulaire français-espagnol, faisant suite au Dictionaire militaire espagnol-français:

Para que la obra fuese completa se hacía preciso poner la correspondencia de las voces francesas al castellano, con sus definiciones en francés, del mismo modo que están las españolas; mas con el fin de economizar su costo, y reducir el Diccionario a un solo volumen para su más fácil manejo, he limitado esta segunda parte a la simple correspondencia de las palabras del francés al español (Moretti 1828: XII).

\subsection{El Vocabulario militar (1849) de Luis Corsini}

Este repertorio consta de una serie de informaciones previas, incluidas en la «Advertencia», de las que subrayamos las relativas a la técnica lexicográfica adoptada, por

${ }^{5}$ Los restantes son: en primer lugar, un «suplemento de algunas voces omitidas en el Diccionario», a continuación, un «apéndice al Diccionario militar castellano y francés, que contiene el manual alfabético razonado de las monedas, pesos y medidas de todos los tiempos y países, con sus reducciones a las equivalencias españolas y francesas» y, por último, un «suplemento de algunas voces omitidas en el Apéndice». 
ser la primera vez que este tipo de observaciones se incorporan en un diccionario militar. En primer lugar, Corsini especifica cuál ha sido su modo de proceder en la ordenación de las múltiples unidades pluriverbales recogidas, asunto en el que decide distanciarse del criterio académico:

El Vocabulario militar componiéndose más bien, en general, de denominaciones compuestas, que de voces sueltas y aisladas, hemos dudado un momento si en él seguiríamos el orden admitido comúnmente para los diccionarios, y que consiste en colocar la frase adverbial o denominadora en el lugar alfabético a que corresponde el primer substantivo que en ella se encuentre. Por fin nos hemos decidido a no admitir esta regla, persuadidos de que, bien que menos académica, y aunque se la tache de poco culta y de muy ramplona, es mucho más sencilla, pronta y cómoda la de buscar la denominación que se quiera encontrar, por la letra o letras iniciales con que de cualquier modo principie aquella (Corsini 1849: XIV).

En segundo lugar, informa a sus lectores acerca de la lematización y del tratamiento otorgado a los términos cuyo uso normalmente es en plural:

Advertiremos también que muchos substantivos o denominaciones compuestas se ponen en plural, ya porque su aplicación más general se hace de este modo, o ya porque el uso ha hecho que sean así más significativas, y mejor o más fácilmente comprendidas (Corsini 1849: XIV).

Por otro lado, al comparar artículos lexicográficos como los siguientes, resulta evidente que Corsini tuvo muy presente para la redacción de su obra el Diccionario militar de Moretti:

\begin{tabular}{|l|l|}
\hline \multicolumn{1}{|c|}{ Moretti (1828) } & \multicolumn{1}{c|}{ Corsini (1849) } \\
\hline $\begin{array}{l}\text { Camisa. s. f. Fort. Chemise. El lado de la } \\
\text { muralla hacia la campaña, que suele hacerse } \\
\text { de piedra blanca o ladrillos blandos. Llámase } \\
\text { camisa por vestir la muralla por la parte de } \\
\text { afuera. }\end{array}$ & $\begin{array}{l}\text { Camisa. s. f. Fort. El lado de la muralla que } \\
\text { cae hacia la campaña, y que suele hacerse de } \\
\text { piedra o ladrillos blandos. Llámase camisa, } \\
\text { en atención a que reviste la muralla por la } \\
\text { parte de afuera. }\end{array}$ \\
\hline $\begin{array}{l}\text { Tenaza. s. f. Fort. Ouvrage à tenaille. Obra } \\
\text { de campaña que se construye para fortificar la } \\
\text { cabeza de un puente o sobre las líneas de } \\
\text { defensa, parecida al hornabeque, y en el foso } \\
\text { entre dos baluartes. La tenaza se distingue en } \\
\text { simple y doble [...]. }\end{array}$ & $\begin{array}{l}\text { construye con el objeto de fortificar la cabeza } \\
\text { en puente, o sobre las líneas de defensa, en } \\
\text { distingue en simple y doble }[. . .] .\end{array}$ \\
\hline
\end{tabular}

No obstante, Corsini no comparte la opinión de Moretti en lo concerniente a la recepción de las voces específicas de la milicia antigua: «Hemos dejado de comprender [...] cuanto tiene relación con las armas desusadas, con los ejércitos de la antigüedad, y con los sistemas y organizaciones caducas» (Corsini 1849: XI).

Por otro lado, decide suprimir «las voces militares cuya definición ha llegado a ser ociosa, por demasiado vulgar y conocida» (Corsini 1849: XI), de nuevo en contraposición a su antecedente más directo. Según especifica más adelante, «sería [...] enteramente ocioso y hasta ridículo perder tiempo y papel en explicarles, con mucha seriedad, cual si fuesen unos doctrinos, los significados de una infinidad de voces comunes y olvidadas de puro sabidas, como son, por ejemplo, las de soldado, tiro, ataque cen- 
tral, ardid, etc.». Ahora bien, pese a esta afirmación, tiro sí forma finalmente parte de la macroestructura de este diccionario ${ }^{6}$, seguramente debido a que designa «acepciones diferentes, que convenía deslindar a fin de evitar el que se confundiesen», tal como confiesa en su prólogo (Corsini 1849: XV).

\subsection{El Diccionario general militar (1857) de Deogracias Hevia}

Del Diccionario general militar de voces antiguas y modernas interesa resaltar que encarna el primer ejemplo de repertorio especializado en la milicia en cuyo prólogo se incorpora «una ligera reseña comparativa de cuantos diccionarios y vocabularios militares, hasta hoy, en castellano vieron la luz pública» (Hevia 1857: v). Aunque no está exenta de algunas faltas e incorrecciones, se trata de una historia de la lexicografía relativa a esta especialidad bastante completa.

Antes de disponerse a explicar el sistema empleado para la confección de su diccionario, Hevia introduce la siguiente reflexión:

Con el frecuente uso que largo tiempo hice, por necesidad y por gusto, de los Diccionarios, así militares como de la lengua, he podido advertir que, así como un periódico da una noticia, y luego la repite otro, y después todos la publican, sin citar la fuente de donde manó, asimismo los lexicógrafos se aprovechan sin el menor escrúpulo de las definiciones que hallan hechas y cumplen a su fin; siendo esta costumbre tan antigua y de tal modo autorizada, que hasta los académicos de la lengua plagiaron sin el menor escrúpulo a Covarrubias, desde la definición de la letra A, cuando publicaron su primer Diccionario, que se llamó de autoridades (Hevia 1857: IX).

De esta forma, admite que «imitando tan eminentes ejemplos, [...] cuando de alguna voz técnica militar hallé hecha la explicación de una manera que me pareció clara, exacta y con las dimensiones adaptables a mi plan, la tomé literalmente» (Hevia 1857: IX). Y, probablemente para no incurrir en la falta que acababa de censurar, decide hacer públicas las obras de las que ha tomado más definiciones: «Y aun diré más, y es que los Sres. Moretti y Corsini son los autores que más trabajo me ahorraron» (Hevia 1857: IX). Ahora bien, al tener en cuenta en su repertorio, como precisa su título, no sólo los tecnicismos militares modernos, sino también los antiguos, es mucho más evidente la huella de Moretti en el Diccionario general militar de Hevia que la de Corsini.

\subsection{El Diccionario militar (1863) de Jorge D'Wartelet}

En su portada se especifica que es obra «del capitán retirado J. D’ W. M.», iniciales que, según la Biblioteca Nacional de España, corresponden a Jorge D’Wartelet. Esta página inicial también informa sobre el tipo de términos contemplados: «Contiene las voces técnicas, términos, locuciones y modismos antiguos y modernos de los ejércitos de mar y tierra». Por lo demás, al tratarse de una obra lexicográfica carente de prólogo, los usuarios no contamos con ninguna otra información proveniente del autor.

${ }^{6}$ «1.- La distancia a que alcanza una arma de fuego cualquiera. 2.- Art. Se llama así al total de caballos que tiran de cada carruage. 3.- Hábito que contraen algunos caballos, de apoyar los dientes en el pesebre, de morder el ronzal, etc., con contracción manifiesta de los músculos del cuello» (Corsini 1849: s. v. tiro). 
Tras la portada D'Wartelet incluye la «esplicación de las abreviaturas». Si se tiene en cuenta que posee una marca específica para las voces pertenecientes a la marina, además del compromiso por recopilar los «términos [...] de los ejércitos de mar y tierra», parece evidente que en la conformación de su macroestructura, además de a la terminología militar terrestre, ha dado cabida a la naval. El único lexicógrafo de especialidad, de todos los estudiados, que también utiliza marca diatécnica de marina es Deogracias Hevia.

Después del catálogo de abreviaturas se ubica el lemario, del que debe notarse su vasta extensión, al componerse de 746 páginas, mientras que por ejemplo el de Hevia, quien remarcaba la amplitud de su trabajo ${ }^{7}$, consta de 465 .

La incorporación de una mayor cantidad de información en sus artículos puede ser uno de los motivos que expliquen por qué D'Wartelet casi consigue doblar el número de hojas de su antecedente más directo. Ahora bien, si se tiene en cuenta que es bastante copioso el conjunto de unidades léxicas que gracias a D'Wartelet entran a formar parte por vez primera de un diccionario de temática militar (algunas de esas voces son dársena, gardingo, voivode, voltigeur, wali y wingher), quizá no debería resultarnos tan extraño el considerable volumen de este.

\subsection{El Diccionario militar (1869) de José Almirante}

En primer lugar, debemos subrayar la extraordinaria magnitud de este repertorio, ya que sólo la parte lexicográfica monolingüe ${ }^{8}$ consta, en la edición consultada, de 1070 páginas. De todas maneras, a partir de los cómputos realizados por Gago-Jover (2008), esta mayor extensión no se traduce en una macroestructura más completa, puesto que, mientras que el Diccionario militar de D'Wartelet posee 7716 entradas, el de Almirante solo cuenta con 5502. Por consiguiente, este aumento se debe a la mayor extensión concedida a los artículos por parte de Almirante. En este sentido, la etimología ${ }^{9}$, que por primera vez aparece en un diccionario militar, contribuye al aumento de aquellos artículos en los que se contempla:

Guarda. Evidentemente la raíz es gótica o teutónica ward, pronunciada guard, y que en el latín bárbaro se convirtió en wardea, wardia guardia; pero no todos los etimologistas están de acuerdo. Monlau, por ejemplo, citando a Rosal, opina por la raíz árabe huad, mano, de donde se hizo huarid, amparo, defensa; de aquí guarida y de éste, guardar, guarecer, guarnecer [...].

${ }^{7}$ «He procurado, por todos los medios que a mi alcance tuve, reunir la colección más rica que jamás en España se haya publicado, de voces técnicas militares, así antiguas como modernas, con tal que hayan tenido y tengan uso en el ejército español» (Hevia 1857: VIII).

8 «Siendo las dos lenguas francesa y alemana las más útiles para el militar español, van al fin dos copiosos Vocabularios, con sus principales equivalentes, cuya definición y explicación se encuentran en el cuerpo del Diccionario» (Almirante 1869: XXVII).

${ }^{9}$ «El tecnicismo militar dista bastante de estar hecho. La misma lengua general no permanece estacionaria; sigue las evoluciones del pueblo que la habla; es, pues, indispensable alguna atención a la etimología, no para entrar en honduras con San Isidoro o Covarrubias, cayendo en la vaguedad o en la manía de forzarlas, sino en cuanto pueda percibirse el origen inmediato de la voz en alguna de las lenguas madres del castellano» (Almirante 1869: XXVII). 
Como él mismo apunta, «la acumulación de citas y textos, la excesiva nimiedad en señalar la obra, la edición, el volumen, la página, bien se ve que no es alarde de erudición, ni jactancia literaria; sino, todo lo contrario, modesto empeño en el autor de robustecer con la de los maestros su escasa autoridad personal» (Almirante 1869: XXVI). Evidentemente, la presentación de este tipo de datos también contribuye al aumento del número de páginas de su obra.

Otra práctica habitual en Almirante es el comentario de las definiciones que ofrecen algunos de los diccionarios militares precedentes, normalmente con el objeto de criticarlos, lo que también conlleva artículos lexicográficos dilatados. Es el caso de, por ejemplo, batalla.

No obstante, ni guarda ni batalla, los dos lemas mencionados, parecen pertenecer al grupo de los que Almirante (1869: XXVII) denomina de «importancia capital», del que cita tres ejemplos: guerra, táctica y artillería. Según él mismo confiesa, era inevitable que términos como éstos estuviesen en el origen de los artículos más largos. Así, no debería sorprendernos que, según nuestra edición, se compongan de 111, 36 y 24 páginas respectivamente.

Con respecto a la técnica lexicográfica empleada en las definiciones ${ }^{10}$, asegura que ha puesto "singular empeño y diligencia en que la definición sea clara, exacta, precisa y breve en lo posible; mas, considerando también que el mejor modo de definir ciertas cosas es trazar su historia, no hemos retrocedido ante la extensión unas veces, ante la divagación otras» (Almirante 1869: XXVI).

Aun con todo, «para disminuir volumen [...], ha parecido conveniente apartarse un poco del camino trillado, haciendo [algunas] supresiones» (Almirante 1869: XXIII). De esta forma, tanto el léxico heráldico, como el relativo a la albeitería quedan al margen de este diccionario. Tampoco admite ni las órdenes militares ni las condecoraciones extranjeras, además de descartar también los términos correspondientes a ejércitos antiguos, como el egipcio, el chino o el tártaro. Sobre este último ámbito, considera que «basta con remontarse a las fuentes de Grecia y Roma» (Almirante 1869: XXIV).

Por último, queremos subrayar el empeño que muestra este lexicógrafo por ofrecer su opinión acerca de determinadas cuestiones lingüísticas:

Embrasura. Los traductores del francés que no saben castellano encuentran embrasure y dicen muy frescos embrasura; otros lo copian, y al verlo impreso en "libros de texto" se ha llegado a creer, no sólo que esta voz es española, sino que da cierto relieve "técnico" al que la pronuncia, por ser algo extraña en efecto. Conste que los franceses son dueños de decir embrasure; pero los españoles tenemos suficiente con cañonera y tronera, sin necesidad de embrasura.

${ }^{10}$ Es la primera vez que vemos en un diccionario de este tipo alguna consideración acerca del modo de proceder seguido en el establecimiento de uno de los elementos lexicográficos más importantes, a saber, la definición. De hecho, Almirante comienza a referir los tipos de definición existentes, convirtiéndose así en el primer autor de un repertorio especializado de la milicia que considera este tema: «Los lexicógrafos reconocen dos clases de definiciones, la explicativa y la sinonímica: esto es, la que admite descripción y la que se limita a dar equivalencias o sinónimos. Algunos sostienen que no puede haber dos palabras rigurosamente sinónimas; pero este segundo método es el más generalmente seguido, porque evita dificultades de redacción y da cierto aspecto de generalidad, que suele degenerar en confusión» (Almirante 1869: XXVI). 
Es por artículos como este por los que en su prólogo Almirante (1869: XXVI) declara que «también se apuntan algunos galicismos usuales, pero innecesarios».

\subsection{El Diccionario de ciencias militares (1895-1901) de Rubió y Bellvé}

Es una obra de gran envergadura que se compone de tres volúmenes. A propósito del nombre de este repertorio, comprobamos cómo en el prólogo su autor se afana por explicar las causas que le han motivado a titularlo así:

La ciencia estudia, el arte ejecuta; la primera analiza, examina, compara, deduce; el segundo da preceptos más o menos terminantes y obra, por cuyo motivo, y prescindiendo de consideraciones de otra índole, no repugna a la lógica llamar ciencias militares al conjunto sistemático de verdades de un mismo orden, y que tienden reunidas a la perfección del arte militar (Rubió y Bellvé 1895: VI).

Según este criterio, el arte militar es un «compendio de todas las ciencias militares» (Rubió y Bellvé 1895: VII). Y, de nuevo en sus propias palabras, «el arte militar, siguiendo un orden lógico, resulta subdividido en tres partes esenciales: los prolegómenos o primeros principios, los medios de guerra, o sea la descripción de la herramienta, y la ejecución de la guerra, o sea el empleo para los fines sociales» (Rubió y Bellvé 1895: VII). Tras estas reflexiones, decide insertar, para facilitar el entendimiento de su anterior exposición, un cuadro sinóptico en el que sintetiza su concepción acerca del arte militar, así como su correspondiente clasificación epistemológica.

Como «en la historia de las ciencias militares brillan algunos individuos cuyos pensamientos y cuyas acciones son casi el arte de la guerra» (Rubió y Bellvé 1895: IX), considera conveniente incluir las biografías de esos personajes, así como las de algunos militares ilustres. Rubió y Bellvé se hace eco de unidades tradicionalmente consideradas exclusivas de las obras enciclopédicas, de las que citamos Alba (Duque de), Espínola (Ambrosio de) o Fernández de Medrano. Además de los antropónimos, los topónimos son también habituales: España, Castilla y San Quintín, por nombrar solo unos ejemplos.

«De muchas palabras se inserta la etimología, y la correspondencia en voces extranjeras» (Rubió y Bellvé 1895: IX). Admite, no obstante, que no ha sido éste su modo de proceder en todos los casos, «por no ser siempre fácil, ni quizá de gran utilidad». Por último, un elevado número de entradas se ve acompañado de ilustraciones.

\subsection{El Diccionario militar (1897) de Nicolás Estévanez}

De acuerdo con su contraportada, comprende, además de la parte monolingüe en nuestra lengua, «un vocabulario español-francés-alemán», disposición que seguramente se deba al influjo de Almirante:

Uno de los mejores [diccionarios], por no decir el mejor de los que existen, el de Almirante, es un verdadero archivo, es un prodigio de erudición militar; pero, como escrito hace cuarenta años, faltan en él todos los términos técnicos y usuales que corresponden a lo mucho nuevo adoptado en el tiempo transcurrido desde que se escribió (Estévanez 1897: v).

Es este uno de los motivos que le impulsan a sacar a la luz su obra. Ahora bien, parece ser, dado que lo reitera en su prólogo, que la razón principal radica en la constata- 
ción de la falta para el castellano de un diccionario militar manual, «que todos los subalternos puedan adquirir y llevar consigo a todas partes» (Estévanez 1897: VI). Pues bien, la mayoría de las características que pueden aducirse sobre este diccionario de 1897, como son la ausencia de datos etimológicos ${ }^{11}$ o la utilización de definiciones brevísimas $^{12}$, responden a este objetivo de lograr un texto conciso, a la vez que práctico.

\section{CONSIDERACIONES FINALES}

Si bien el presente trabajo se trata de una primera aproximación al corpus lexicográfico militar de los siglos XVIII y XIX, pueden extraerse varias conclusiones. La más importante es la escasez de repertorios militares del XVIII en comparación con los publicados durante todo el siglo XIX. Así, de los once diccionarios contemplados, solo dos pertenecen a la primera de estas dos centurias. Además, mientras que estos son traducciones de dos obras lexicográficas francesas, los otros nueve suponen las primeras aportaciones originales a este ámbito por parte de lexicógrafos españoles o bien afincados en nuestro país. En definitiva, el siglo XIX es el del nacimiento de la lexicografía militar monolingüe inicialmente redactada en nuestra lengua.

Por otro lado, desde que en 1822 Fernández Mancheño publica su Diccionario militar portátil hasta el año 1901, cuando ve la luz el último de los tres tomos del Diccionario de ciencias militares de Mariano Rubió y Bellvé, el ritmo de aparición de este tipo de obras es sumamente fluido, lo que supone que el siglo XIX sea también el más productivo respecto a la publicación de diccionarios centrados en el arte militar.

Dada esta vasta parcela de investigación, nuestro propósito es seguir ahondando en ella; así, otra posibilidad de estudio sería aquella que contemplase los repertorios plurilingües, además de la que diese cabida a los referidos a disciplinas especializadas de la milicia o afines a ella.

\section{REFERENCIAS BIBLIOGRÁFICAS}

AGAR, L. (1853-1866): Diccionario ilustrado de los pertrechos de guerra y demás efectos pertenecientes al material de artillería, Madrid, Lit. Tormentaria de C. Echauri.

Almirante, J. (2002 [1869]): Diccionario militar. Madrid: Ministerio de Defensa.

Aut. Real ACAdemia Española (1990 [1726-1739]): Diccionario de Autoridades, Madrid, Gredos.

Biblioteca Nacional de España (BNE). Disponible en: $<\mathrm{http}: / /$ www.bne.es/es/inicio/index. html $>$ [Consulta: 22 de febrero de 2012].

CASTAÑón, L. (1791-1792): Encyclopedia metódica, Madrid, Imprenta de Sancha.

CORSINI, L. (1849): Vocabulario militar, Madrid, Imprenta del Semanario e Ilustración.

${ }^{11}$ «Nuestro objeto no es dilucidar si una voz técnica procede del latín, del escandinavo o del caldeo, sino ofrecer un índice de expresiones militares, de términos empleados en la milicia española, de palabras hoy en desuso, que a veces llenan de dudas y confusiones al lector de libros militares» (Estévanez 1897: V).

12 «En general nos hemos limitado a la definición brevísima de cada voz, con el propósito de hacer un libro portátil y barato» (Estévanez 1897: VI). 
D’ Wartelet, J. (1863): Diccionario militar, Madrid, L. Palacios.

ENRILE, J. M. (1853): Vocabulario militar francés e inglés-español, París, H. Vrayet de Surcy.

ESTÉVANEZ, N. (1897): Diccionario militar con un vocabulario español-francés-alemán, París, Garnier Hermanos.

FERNÁNDEZ MANCHEÑO, J. (1822): Diccionario militar portátil, o recopilación alfabética de todos los términos propios de las ciencias militares, explicación de los empleos de la milicia y sus obligaciones [...], Madrid, Imprenta de Miguel de Burgos.

GAGO-Jover, F. (2007): «Léxico militar del siglo XVIII: El Diccionario militar de Raimundo Sanz», en M. Campos Souto, R. Cotelo García y J. I. Pérez Pascual, eds., Historia de la lexicografía española, A Coruña, Universidade da Coruña, pp. 59-67.

GAGO-Jover, F. (2008): «Glosarios y diccionarios militares del siglo XIX», en Azorín, D. et alii (eds.): El diccionario como puente entre las lenguas y culturas del mundo. Actas del II Congreso Internacional de Lexicografia Hispánica, Alicante, Universidad de Alicante-Fundación Biblioteca Virtual Miguel de Cervantes, pp. 670-677.

GAgo-Jover, F. y F. TeJedo-HerRero (2007): «Introducción», en R. Sanz, Diccionario militar, Zaragoza, Institución Fernando el Católico, pp. VI-XXI.

GARCÍA PlATERO, J. M. (2003): «La lexicografía no académica en los siglos XVIII y XIX», en A. M. Medina Guerra, A. M., coord., Lexicografía española, Barcelona, Ariel, pp. 263-280.

GARRIDO, A. (1885): Vocabulario militar español-alemán, Madrid, Diego Pacheco.

HeviA, D. (1857): Diccionario general militar de voces antiguas y modernas, Madrid, Imprenta y estereotipia de M. Rivadeneyra.

Moretti, F. (1828): Diccionario militar español-francés, Madrid, Imprenta Real.

RuBió y Bellvé, M. (1895-1901): Diccionario de ciencias militares, Barcelona, Administración de la Revista cientifico-militar y Biblioteca militar.

SÁnchez Cisneros, J. (1826): Ensayo de un diccionario razonado sobre la ciencia de la guerra, Barcelona, Oficina de la viuda de Don Agustín Roca.

SANZ, R. (1749): Diccionario militar, o recolección alfabética de todos los términos propios al arte de la guerra [...], Barcelona, Imprenta de Juan Piferrer.

SANZ, R. (2007 [1749]): Diccionario militar, edición y estudio de Francisco Gago-Jover y Fernando Tejedo-Herrero, Zaragoza, Institución Fernando el Católico.

TAMARIT, E. (1853): Vocabulario técnico del material de artillería e ingenieros, Madrid. Imprenta de la Biblioteca del Notariado.

TRÉPIED, H. (1889): Vocabulaire militaire espagnol-français, París, Librairie militaire de L. Baudoin.

WiLlson, J. (1794): A pocket vocabulary in six languages, viz. English, German, Dutch, French, Italian and Spanish [...,. Londres, R. Hindmarsh. 